\title{
METODE EDUKASI \& PENDAMPINGAN TERHADAP PENINGKATAN KESADARAN TERKAIT PENGGUNAAN APT PENGRAJIN PANDAI BESI
}

\section{EDUCATION \& ASSISTANCE METHODS ON AWARENESS IMPROVEMENT RELATED TO USE OF EAR PROTECTIVE TOOLS ON BLACKSMITH CRAFTSMAN}

\author{
Atjo Wahyu ${ }^{1}$, Furqaan Naiem ${ }^{2}$, Tahir Abdullah ${ }^{3}$, Yahya Thamrin ${ }^{4}$ \\ ${ }^{1}$ Bagian Kesehatan dan Keselamatan Kerja, Fakultas Kesehatan Masyarakat, \\ Universitas Hasanuddin \\ ${ }^{2}$ Bagian Kesehatan dan Keselamatan Kerja, Fakultas Kesehatan Masyarakat, \\ Universitas Hasanuddin \\ ${ }^{3}$ Bagian Kesehatan dan Keselamatan Kerja, Fakultas Kesehatan Masyarakat, \\ Universitas Hasanuddin \\ ${ }^{4}$ Bagian Kesehatan dan Keselamatan Kerja, Fakultas Kesehatan Masyarakat, \\ Universitas Hasanuddin
}

Alamat Korespondensi: Fakultas Kesehatan Masyarakat Universitas Hasanuddin, Makassar, 90245 HP: +6285395981838, Email: atjowahyu.2006@gmail.com

\begin{abstract}
Abstrak
Kesadaran akan kebisingan di sektor industri khsusnya pengrajin pandai besi umumnya belum diketahui secara luas, sehingga pekerja tidak memperhatikan risiko gangguan kesehatan berupa ketulian akibat paparan kebisingan yang melebihi standar terlebih jika mereka tidak menggunakan penutup telinga (earplug/earmuff). Studi ini merupakan penelitian kuantitatif dengan desain Quasi experiment dengan jumlah sampel 30 orang pekerja pengrajin pandai besi di Kecamatan Tellu Limpoe Kabupaten Sidrap Tahun 2018. Data yang terkumpul kemudian dianalisa yang membandingkan antara pengetahuan, sikap, dan praktik sebelum dan setelah dilakukan metode edukasi serta pendampingan. Hasil diperoleh bahwa melalui metode edukasi serta pendampingan efektif meningkatkan pemahaman pekerja atas kaidah keselamatan dan kesehatan kerja, diperoleh responden berpengetahuan cukup sebelum edukasi dan pendampingan sebesar $66.7 \%$ meningkat menjadi $96.7 \%$. Faktor sikap, responden dengan kategori sikap cukup sebesar $43.3 \%$ meningkat menjadi $100 \%$. Penilaian atas praktek, sebelum pendampingan kategori dengan praktek cukup sebesar $33.3 \%$ dan setelah pendampingan signifikan meningkat menjadi $90 \%$. Olehnya disarankan bagi pemilik usaha dan instansi terkait mempromosikan dan mengsosialisasikan pelaksanaan keselamatan dan kesehatan kerja pada pengrajin besi khususnya perlindungan diri atas sumber bising yang dapat menyebabkan ketulian.
\end{abstract}

Kata kunci : Edukasi, APT, Pandai Besi, Sikap, Pengetahuan

\begin{abstract}
Awareness of noise in the industrial sector especially blacksmith craftsmen is not widely known, so workers do not pay attention to the risk of health problems in the form of deafness due to exposure to noise that exceeds the standard, especially if they do not wearing earplugs/earmuffs. This study is a quantitative design study Quasi experiment with a sample of 30 blacksmith craftsmen in Tellu Limpoe Subdistrict, Sidrap Regency in 2018. The data collected was then analyzed comparing knowledge, attitudes, and practices before and after the education and mentoring methods were conducted. The results were obtained that through effective education and mentoring methods to improve workers' understanding of occupational safety and health rules, obtained sufficient knowledge of respondents before education and assistance of $66.7 \%$ increased to $96.7 \%$. The attitude factor, respondents with a sufficient attitude category of $43.3 \%$ increased to $100 \%$. Assessment of practice, before mentoring the category with enough practice at $33.3 \%$ and after significant assistance increased to 90\%. Therefore, it is recommended for business owners and related agencies to promote and socialize the implementation of occupational safety and health for iron craftsmen, especially self-protection against noise sources that can cause deafness.
\end{abstract}

Keywords: Education, ear protectors, Blacksmith, Attitude, Knowledge 


\section{PENDAHULUAN}

Rendahnya daya serap angkatan kerja khususnya sektor formal, menjadikan para pekerja berusaha mencari atau menciptakan lapangan kerja secara mandiri agar mampu survive. Menurut Badan Pusat Statistik (2018), di Indonesia setidaknya terdapat 53.09 juta orang $(41.78 \%)$ bekerja pada sektor formal dan 73.98 juta orang $(58.22 \%)$ bekerja pada sektor informal. Salah satu bukti wujud kemandirian disektor informal yakni home industry diantaranya industri pandai besi. Namun, issue industri memiliki standar kesejahteraan dan keselamatan pekerja yang minim dan menimbulkan berbagai kerugian khususnya bagi pekerja menjadikan poin utama pentingnya mengevaluasi segala bentuk proses kerja yang berlangsung.

$$
\text { Menurut CDC (2017), }
$$

permasalahan pekerja di sektor industri umumnya dikaitkan dengan paparan kebisingan dengan bahan kimia ototoksik (trikloretilen, logam berat, dan asfiksia) yang dapat menyebabkan kerusakan pada telinga bagian dalam, padahal melalui tindakan sederhana dengan menghindari eksposur setidaknya dapat mencegah risiko.

World Health Organization (2019), mengestimasikan 466 juta orang di seluruh dunia menderita gangguan pendengaran dan diprediksi pada tahun 2050 lebih dari 900 juta orang akan mengalami gangguan pendengaran.

$$
\text { Menurut Reddy et al (2012), }
$$
kebisingan di tempat kerja merupakan kontributor signifikan atas gangguan pendengaran di seluruh dunia, di selandia baru permasalahan ini bukan hanya berdampak pada manusia namun pada perekonomian yang menelan biaya sekitar \$53 juta per tahun dan terus meningkat. Temuan terkait kebisingan di tempat kerja merupakan penyebab signifikan gangguan pendengaran juga dibuktikan Nelson et al (2005), menyatakan bahwa di seluruh dunia $16 \%$ dari gangguan pendengaran yang dialami orang dewasa disebabkan atas kebisingan di tempat kerja.

Studi prospektif yang dilaksanakan Pelegrin (2015) membuktikan, sebagian besar pekerja yang tidak pernah melaksanakan praktik perlindungan atas pendengaran memiliki kelainan audiometrik $(94,1 \%)$, kemudian analisisa regresi menunjukkan prediktor signifikan gangguan pendengaran pada pekerja yang terpapar kebisingan yakni tindakan perlindungan pendengaran $(\mathrm{OR}=12.30, \mathrm{CI}$ =4.36-13.81, $\mathrm{P}<0.001)$ dan durasi paparan kebisingan $(\mathrm{OR}=1.35, \mathrm{CI}=1.08-1.99, \mathrm{P}=$ 0,040). Konsistensi temuan terdahulu atas gangguan pendengaran pekerja industri turut dibuktikan Feder (2017) pada pekerja kanada, diperkirakan $42 \%$ responden 
melaporkan paparan kebisingan di tempat kerja dan setelah 10 tahun atau lebih dikaitkan dengan gangguan pendengaran.

Nilai jual atas produktivitas pekerja pengrajin pandai besi memang menggembirakan, akan tetapi tanpa mereka sadari setiap harinya mereka terpapar eksposur. Menurut Muflichatun (2006), orang yang bekerja di sektor pandai besi selain dapat mengalami gangguan kesehatan auditoir dan non auditoir, juga dapat terpapar suhu panas, dengan sanitasi lingkungan kerja pun yang tidak memenuhi standar. Di Indonesia, data terkait pengrajin pandai besi terbilang belum terdata dengan baik, namun nyatanya alat-alat yang diciptakan sangatlah dibutuhkan dalam kehidupan sehari-hari diantaranya : besi, meuble, pemotong kayu, gergaji listrik, dan lain sebagainya, sehingga perhatian penting pada industri ini perlu dilaksanakan.

Salah satu kabupaten pengrajin pandai besi dengan ikon sentra usaha pengrajin pandai besi adalah Kabupaten Sidrap, dimana hasil produksinya tidak hanya dipasarkan di daerah Sulawesi akan tetapi hingga berbagai pulau di Indonesia (Kalimantan, Papua dan daerah lainnya). Rata- rata hasil produksi yang diperoleh sekitar 289.950 buah berupa parang, pisau, sabit, cangkul dan alat-alat pertanian. Namun, studi terbaru Fadli (2016) pada salah satu wilayah pengrajin besi di Kabupaten Sidrap menemukan bahwa, sekitar $\quad 70 \%$ tempat/titik memiliki intensitas kebisingan yang tidak memenuhi syarat $(>85 \mathrm{~dB})$ dan $82,5 \%$ pekerja mengalami gangguan pendengaran atau penurunan daya dengar.

Berdasarkan fakta dan temuan studi, nyatanya kesadaran akan bahaya kebisingan masih kurang dipahami para pekerja, padahal kondisi kesehatan dan keselamatan kerja para pandai besi sangat memprihatinkan sehingga diperlukan upaya yang nyata dalam meningkatkan kesadaran khususnya penggunaan Alat Pelindung Telinga (APT) pada saat melaksanakan tugas agar pekerja dapat terhindar atau setidaknya meminimalisir risiko penyakit gangguan pendengaran. Oleh karena itu, untuk mempermudah dan mempercepat pemahaman tentang pentingnya pemakaian alat pelindung telinga maka peneliti bermaksud melakukan eksperimen sederhana melalui media flip chart sebagai langkah awal menjembatani dalam membangun pendidikan kesehatan (pengetahuan, sikap, dan praktik) yang efektif bagi pekerja terutama pada pekerja sektor informal dibidang pengrajin pandai besi.

Melalui eksperiman sederhana berupa edukasi dan pendampingan ini diharapkan dapat meningkatkan derajat kesehatan dan keselamatan pekerja yang lebih berhubungan dengan perubahan perilaku hidup dan perilaku bekerja. 
Sehingga tujuan studi ini yakni, untuk mengetahui efektifitas edukasi dan pendampingan terhadap peningkatan kesadaran penggunaan alat pelindung telinga pada pengrajin pandai besi di wilayah Kabupaten Sidrap khususnya di Kecamatan Tellu Limpoe.

\section{METODE}

\section{Lokasi dan Rancangan Penelitian}

Penelitian ini dilaksanakan di lokasi para pengrajin besi di wilayah Kabupaten Sidrap tepatnya di Kecamatan Tellu Limpoe pada September-Oktober tahun 2018. Rancangan studi menggunakan penelitian kuantitatif dengan desain eksperimen semu (Quasi experiment design).

\section{Populasi dan sampel}

Populasi studi yakni seluruh pengrajin besi yang bertempat tinggal di wilayah Kecamatan Tellu Limpoe. Adapun sampel yakni pengrajin besi yang bersedia di wawancarai dan hadir dalam pelatihan dan untuk meningkatkan kesadaran, pengetahuan, sikap dan perilaku pada pengrajin pandai besi Kabupaten Sidrap khusunya di Kecamatan Tellu Limpoe, adapun jumlah sampel yakni 30 responden.

\section{Metode pengumpulan data}

Metode pengumpulan data dalam riset ini yakni para pengrajin besi di undang menghadiri proses edukasi dalam rangka meningkatkan kesadaran, pengetahuan, sikap dan perilaku, dimana sebelum dilaksanakannya edukasi dan pendampingan selama dilapangan, para pengrajin mengisi lembar observasi (pre test) dan setelah beberapa waktu maka dilakukan proses observasi kembali (post test).

Materi yang diberikan kepada responden yakni terkait upaya berperilaku selamat dan sehat dalam bekerja, berbagai hazard yang ada di lingkungan kerja pengrajin pandai besi dan sistem pengendaliannya, hingga mengenalkan secara langsung penggunaan alat APT secara baik dan benar, adapun waktu yang dibutuhkan dalam pendampingan praktek penggunaan Alat Pelindung Diri (APD) yakni 3 hari.

\section{Analisis data}

Data yang dikumpulkan diolah dengan bantuan software SPSS (Statistical Package for Sosial Science), yang kemudian di sajikan dalam bentuk tabel disertai penjelasan.

\section{HASIL}

\section{Karakteristik Responden}

Hasil penelitian berdasarkan tabel 1 menunjukkan bahwa, dari keseluruhan responden, umumnya mereka berada pada kelompok umur dewasa tua yaitu sebanyak 93.3\% sedangkan kelompok umur dewasa muda dan lanjut usia masing-masing 3.3\%. Terkait tingkat pendidikan terkahir, terdapat 13 orang $(43.3 \%)$ pada kelompok 
sekolah dasar, 8 orang tingkat SMP (26.7\%), SMA 7 orang $(23.3 \%)$ dan terdapat 2 orang $(6.7 \%)$ yang tidak sekolah. Untuk masa kerja lebih dari setengah jumlah responden berada pada kelompok dengan masa kerja lama (>10 tahun) yaitu 19 orang $(63.3 \%)$, hanya 2 orang $(67.0 \%)$ di antaranya pada kategori masa kerja baru atau 1-5 tahun.

Tabel 1 : Karakteristik Responden

\begin{tabular}{lcc}
\hline \multicolumn{1}{c}{ Karakteristik Responden } & n & \% \\
\hline Umur & 1 & 3.3 \\
$\quad$ Dewasa Muda & 28 & 93.3 \\
$\quad$ Dewasa Tua & 1 & 3.3 \\
$\quad$ Lanjut Usia & & \\
Tingkat pendidikan & 2 & 6.7 \\
$\quad$ Tidak Sekolah & 13 & 43.3 \\
SD & 8 & 26.7 \\
SMP & 7 & 23.3 \\
SMA & & \\
Masa Kerja & 2 & 6.7 \\
Baru (1-5 th) & 9 & 30. \\
Sedang (6-10 th) & 19 & 63.3 \\
Lama (>10 th)
\end{tabular}

Sumber: Data Primer, 2018

Tabel 2: Perbandingan Rata-rata Tingkat Pengetahuan Menggunakan Alat Pelindung Telinga pada Pengrajin Pandai Besi di Kecamatan Tellu Limpoe Kabupaten Sidrap

\begin{tabular}{clccc}
\hline Item & \multicolumn{1}{c}{ Pertanyaan } & $\begin{array}{c}\text { Pre } \\
\text { Test }\end{array}$ & $\begin{array}{c}\text { Post } \\
\text { Test }\end{array}$ & Selisih \\
\hline 1 & $\begin{array}{l}\text { APD melindungi diri dari bahaya dan } \\
\text { risiko di tempat Kerja. }\end{array}$ & 0.93 & 1.00 & 0.07 \\
2 & $\begin{array}{l}\text { Kondisi bising di tempat kerja Pengrajin } \\
\text { Pandai }\end{array}$ & 0.37 & 0.87 & 0.5 \\
3 & $\begin{array}{l}\text { Penggunaan APT dapat menurunkan risiko } \\
\text { gangguan pendengaran }\end{array}$ & 0.9 & 1.00 & 0.1 \\
$4 \quad \begin{array}{l}\text { Personal hiegene yg baik mencegah dari } \\
\text { penyakit kulit }\end{array}$ & 0.83 & 1.00 & 0.17 \\
5 & $\begin{array}{l}\text { Pekerjaan yang melebihi 7 jam kerja dalam } \\
\text { sehari dapat berakibat buruk pada kesehatan }\end{array}$ & 0.73 & 0.93 & 0.20 \\
\hline
\end{tabular}
Sumber: Data Primer, 2018

Rata-rata tingkat pengetahuan pengetahuan mengenai penggunaan alat penggunaan $A P D$ pelindung diri dalam mencegah ketulian

Meninjau tabel 2 berdasarkan akibat bising menunjukkan bahwa, pengukuran dari 5 item indikator pengetahuan pekerja rata-rata mengalami 
peningkatan setelah dilaksanakan edukasi dan pendampingan kaidah keselamatan dan kesehatan kerja pada pengrajin pandai besi, terutama mengenai kondisi bising di tempat kerja. Peningkatan nilai mean pre-post sebesar 0.07 pada pertanyaan alat pelindung diri seperti topi, penutup telinga (earplug/earmuff), sarung tangan, masker, dan sepatu digunakan untuk melindungi diri dari bahaya dan risiko di tempat kerja, hal ini dikarenakan sebelum pelatihan berlangsung sebagian besar telah mengetahui jenis-jenis APD di tempat kerjanya yaitu sebesar 0.93 .

Tabel 3: Perbandingan Rata-rata Sikap dalam Penggunaan Alat Pelindung Telinga pada Pengrajin Pandai Besi di Kecamatan Tellu Limpoe Kabupaten Sidrap

\begin{tabular}{clccc}
\hline Item & \multicolumn{1}{c}{ Pertanyaan } & $\begin{array}{c}\text { Pre } \\
\text { Test }\end{array}$ & $\begin{array}{c}\text { Post } \\
\text { Test }\end{array}$ & Selisih \\
\hline $1 \quad \begin{array}{l}\text { Memakai Alat pelindung diri secara } \\
\text { lengkap dan benar meskipun agak } \\
\text { mengganggu }\end{array}$ & 3.3 & 3.77 & 0.47 \\
$2 \quad \begin{array}{l}\text { Tidak ada hubungan antara pemakaian APT } \\
\text { dengan gangguan pendengaran }\end{array}$ & 2.30 & 3.27 & 0.97 \\
$3 \quad \begin{array}{l}\text { Pemakaian APD secara baik sangat penting } \\
\text { untuk menjaga K3 }\end{array}$ & 1.53 & 3.70 & 2.17 \\
$4 \quad \begin{array}{l}\text { Memaksakan diri bekerja lebih dari 7 jam agar } \\
\text { penghasilan banyak }\end{array}$ & 2.53 & 3.27 & 0.74 \\
5 & $\begin{array}{l}\text { Membiasakan mandi setelah melakukan } \\
\text { aktivitas pekerjaan }\end{array}$ & 3.6 & 3.87 & 0.27 \\
\hline
\end{tabular}

Sumber: Data Primer, 2018

Tabel 4: Perbandingan Rata-rata Praktek dalam Penggunaan Alat Pelindung Telinga pada Pengrajin Pandai Besi di Kecamatan Tellu Limpoe Kabupaten Sidrap

\begin{tabular}{|c|c|c|c|c|}
\hline Item & Pertanyaan & $\begin{array}{l}\text { Pre } \\
\text { Test }\end{array}$ & $\begin{array}{l}\text { Post } \\
\text { Test }\end{array}$ & Selisih \\
\hline 1 & Saya memakai alat pelindung telinga & 2.4 & 3.6 & 1.2 \\
\hline 2 & $\begin{array}{l}\text { Saya memakai topi pengaman pada saat } \\
\text { bekerja }\end{array}$ & 2.27 & 3.43 & 1.16 \\
\hline 3 & Saya tidak memakai Masker pada saat bekerja & 2.63 & 3.03 & 0.4 \\
\hline 4 & $\begin{array}{l}\text { Saya memakai Sarung tangan pada saat } \\
\text { bekerja }\end{array}$ & 2.43 & 3.37 & 0.94 \\
\hline 5 & $\begin{array}{l}\text { Saya tidak mandi dan membersihkan diri } \\
\text { setelah bekerja }\end{array}$ & 2.67 & 3.70 & 1.03 \\
\hline 6 & $\begin{array}{l}\text { Saya memakai alat pelindung kaki (Sepatu } \\
\text { kerja) pada saat bekerja. }\end{array}$ & 2.13 & 2.47 & 0.34 \\
\hline
\end{tabular}

Sumber: Data Primer, 2018

\section{Rata-rata sikap dalam penggunaan APD}

Berdasarkan pengukuran dari 5 item indikator sikap mengenai penggunaan alat pelindung telinga pada pengrajin pandai besi tabel 3 menunjukkan bahwa sikap pekerja rata-rata mengalami peningkatan, 
indikator tertinggi setelah pelaksanaan edukasi dan pendampingan yakni mengenai pemakaian APD secara baik sangat penting untuk menjaga keselamatan dan kesehatan kerja sebesar 2.17. Namun, mengenai poin membiasakan mandi setelah melakukan aktivitas pekerjaan mengalami perubahan nilai mean tidak cukup signfikan yaitu hanya sebesar 0.27, hal ini dikarenakan pekerja telah mengetahui dan menerapkan baik sebelum dan setelah diadakan edukasi mengenai kebiasaan mandi.

\section{Rata-rata praktek penggunaan APD}

Berdasarkan 6 item indikator terkait praktek mengenai penggunaan alat pelindung diri terutama APT pada pengrajin pandai besi menunjukkan, semua item indikator praktek mengalami peningkatan setelah di berikan edukasi dan pendampingan terdapat peningkatan yang cukup tinggi mengenai Saya memakai alat pelindung telinga yaitu sebesar 1.2 Perubahan nilai mean yang terendah berada pada poin Saya memakai alat pelindung kaki (Sepatu kerja) pada saat bekerja 0.34.

Tabel 5. Tingkat Pengetahuan, Sikap dan Praktek dalam Menggunakan Alat Pelindung Telinga pada Pengrajin Pandai Besi di Kecamatan Tellu Limpoe Kabupaten Sidrap

\begin{tabular}{ccccc}
\hline \multicolumn{1}{r}{ Variabel } & \multicolumn{2}{c}{ Sebelum } & \multicolumn{2}{c}{ Setelah } \\
\cline { 2 - 5 } & n & \% & n & \% \\
\hline Pengetahuan & 20 & 66.7 & 29 & 96.7 \\
a. Cukup & 10 & 33.3 & 1 & 3.3 \\
b. Kurang & 13 & 43.3 & 30 & 100.0 \\
Sikap & 17 & 56.7 & 0 & 0.00 \\
$\quad$ a. Cukup & 10 & 33.3 & 27 & 90.0 \\
b. Kurang & 20 & 66.7 & 3 & 10.0 \\
Praktek & & & & \\
a. Cukup &
\end{tabular}

Sumber: Data Primer, 2018

Hasil analisa tingkat Tingkat Pengetahuan, Sikap dan Praktek dalam penggunaan alat pelindung telinga tabel.5, responden berpengetahuan cukup sebelum edukasi dan pendampingan sebanyak 20 responden $(66.7 \%)$ secara signifikan mengalami peningkatan jumlah menjadi 29 responden (96.7\%). Faktor sikap, responden dengan kategori sikap cukup sebanyak 13 responden $(43.3 \%)$ secara signifikan turut meningkat menjadi 30 responden (100\%). Penilaian atas praktek, sebelum pendampingan kategori dengan praktek cukup sebanyak 10 responden (33.3\%) dan setelah pendampingan secara signifikan meningkat menjadi 27 responden (90\%).

\section{PEMBAHASAN}

Penelitian menunjukkan bahwa terdapat peningkatan pengetahuan, sikap 
dan praktik terkait pentingnya menggunakan alat pelindung telinga (APT) sebagai bentuk pengendalian pencegahan gangguan pendengaran oleh pengrajin pandai besi di wilayah Kabupaten Sidrap khusunya di Kecamatan Tellu Limpoe, setelah dilaksanakan edukasi dan pendampingan sebagai upaya untuk mencegah ketulian akibat bising.

Tenaga kerja yang sehat dan produktif merupakan asset penting dalam peningkatan keberhasilan suatu perusahaan atau tempat kerja, sehingga sebuah perusahaan atau industri harus mampu memberikan fasilitas terbaik seperti kesejahteraan ataupun kenyamanan sehingga mereka dapat bekerja secara maksimal dan mendukung tingkat produktivitas. Bukti pentingnya kesejahteraan pekerja ditemukan Aslpoor \& Amirnejad (2016), dimana kesejahteraan bagi pekerja (seperti : medis, asuransi, transportasi, perumahan, budaya, dan lainlain) memberikan pengaruh positif/signifikan terhadap hasil kinerja pekerja. Hasil atas pemberian kesejahteraan pekerja juga ditemukan Pushpakumari (2008); Lagat et al (2014) ; Waititu et al (2017) ; Moruri et al (2018) yang signifikan meningkatkan kinerja.

Temuan Al-Omari \& Okasheh (2017) menyebutkan bahwa, kendala situasional di lingkungan kerja dapat terdiri dari faktor-faktor seperti kebisingan, fasilitas kantor, ventilasi dan cahaya, padahal faktor tersebut merupakan kondisi lingkungan kerja utama yang menghasilkan dampak negatif pada kinerja olehnya harus mendapatkan perhatian khusus. Temuan ini mengindikasikan bahwa dalam suatu lingkungan kerja pihak manajemen harus mampu mengidentifikasi potensi hazard yang dapat menghambat performance pekerja dan merancang program terbaik dalam meningkatkan produktivitas. Menurut Cancelliere et al (2011), peningkatan produktivitas turut dapat dilakukan melalui strategi sederhana berupa promosi kesehatan yang sekalipun umum digunakan namun manfaatnya dapat menciptakan lingkungan kerja yang positif dan membantu mengurangi risiko kesehatan dan meningkatkan produktivitas.

Tidak terkecuali bagi para pekerja industri yang menghadapi permasalahan kebisingan yang berdampak pada gangguan pendengaran atau penurunan daya dengar, pun harus memperhatikan keselamatan dalam bekerja. Oshima et al (2010) menyatakan, gangguan pendengaran adalah defisit sensorik yang paling sering dalam populasi manusia dan dapat terjadi pada setiap tingkatan usia, adapun kehilangan pendengaran berkisar dari ringan hingga berat tergantung paparannya dan intensitas. Khususnya bagi pekerja, Kirchner et al., (2012) menemukan, individu dengan gangguan pendengaran akibat kebisingan 
dapat mengalami morbiditas, memengaruhi komunikasi pekerja, dan keselamatan secara keseluruhan.

Hasil studi eksperimen ini membuktikan, terdapat peningkatan pengetahuan (30\%), sikap $(56.7 \%)$, dan praktik $(56.7 \%)$ atas pelaksanaan edukasi dan pendampingan terkait kaidah kesehatan dan keselamatan di tempat kerja khususnya upaya untuk mencegah ketulian akibat bising bagi para pekerja. Peningkatan pengetahuan, sikap, dan praktik terhadap gangguan pendengaran akibat kebisingan juga ditemukan Sayapathi et al (2014) namun pada subjek yang berbeda yakni pekerja industri mobil setelah diberikan edukasi kesehatan (pamphlet).

Temuan Keppler et al (2015) terkait efek dari program edukasi atas pendengaran pada paparan kebisingan menunjukkan, terdapat pengaruh antara edukasi yang diberikan dengan perilaku yang lebih melindungi pendengaran pada partisipan dewasa muda. Studi Leshchinsky (2018) terkait kesadaran pekerja dalam menggunakan atau menjaga fungsi pendengaran menunjukkan bahwa, dengan dilaksanakannya tes pendengaran tahunan sebagai hearing conservation program (HCP) menjadikan lebih dari setengah responden mengubah kebiasaan mereka di tempat kerja dan di rumah atau terjadi peningkatan kesadaran penggunaan perlindungan.
Studi terkait pentingnya program edukasi dalam meningkatkan kesadaran pada industri pengrajin pandai besi terkait kebisingan masih terbilang terbatas, namun melihat fakta dari berbagai studi terkait risiko yang ditimbulkan akibat paparan kebisingan menimbulkan risiko gangguan pendengaran (Nandi \& Dhatrak., 2008 ; Heupa et al., 2011 ; Lobato et al., 2014 ; Ahmadi et al., 2014 ; Lie et al., 2016 ; Khoshakhlagh \& Ghasemi., 2017), dan berbagai temuan bahwa pekerja tidak menyadari efek berbahaya dari kebisingan pada kesehatan mereka yang terbukti atas rendahnya pengetahuan, sikap, dan praktik (Ismail et al., 2013 ; Eziyi et al., 2015) menjadikan program edukasi, dan pendampingan kaidah keselamatan kerja harus dilaksanakan, serta pemberian program konservasi pendengaran yang menekankan pada penggunaan alat pelindung pendengaran.

Hal menarik yang turut menjadi perhatian atas permasalahan kebisingan ditemukan pada studi Rus et al (2008), dimana mayoritas pekerja industri penggergajian kayu Kota Bharu-Kelantan menduga, permasalahan gangguan pendengaran bisa disembuhkan hanya dengan minum obat padahal setelah terjadi penurunan fungsi pendengaran kondisi ini belum diketahui dapat disembuhkan atau tidak sama sekali, dalam artian persepsi 
pekerja ini dapat menjadikan mereka mengabaikan bahaya terhadap kebisingan.

Bagaimanapun menerapkan segala kaidah kesehatan dan keselamatan kerja di tempat kerja sangatlah penting, dan ketika penerapan telah dilaksanakan perlu dilaksanakan evaluasi program dalam menilai efektifitasnya, sehingga perbaikan dan peningkatan kualitas kerja serta perlindungan sumber daya manusia dapat dilakukan secara berkesinambungan seiring perkembangan zaman tekhnologi. Tak terkecuali di sektor industri pengrajin pandai besi dapat secara penuh atau bertahap menerapkan kaidah keselamatan kerja.

\section{KESIMPULAN DAN SARAN}

Meninjau terjadinya peningkatan sikap, pengetahuan, dan praktek atas kaidah-kaidah K3 maka edukasi dan pendampingan secara nyata dinyatakan berhasil atau tepat khususnya pada pengrajin besi di wilayah studi sehingga diharapkan, dilaksanakannya program kerjasama antara petugas kesehatan dengan petugas lapangan dan pemilik usaha dalam mempromosikan dan mengsosialisasikan pelaksanaan K3 pada pengrajin besi, serta lebih mengaktifkan kader UKK agar mereka dapat secara intensif memberikan informasi baik diminta maupun tidak untuk meningkatkan pengetahuan, sikap, maupun tindakan pada pengrajin pandai besi yang berpendidikan.

\section{DAFTAR PUSTAKA}

Ahmadi A.A., Gobabaei F., \& Nasiri P. (2014). A Survey of The Effect of Toluene on The Impact of Noise on Hearing Loss in Workers. Journal of Occupational Health And Epidemiology, 3(4):233-241.

Al-Omari K., \& Okasheh H. (2017). The Influence of Work Environment on Job Performance: A Case Study of Engineering Company in Jordan. International Journal of Applied Engineering Research, 12(24):15544-15550.

Alzahrani R.A., Alzahrani A.O., Alghamdi A.A., MA A., Alamri A.H., Alghamdi S.G., \& Alzahrani F.A. (2018). Knowledge, Behaviors, and Attitudes about Noise-induced Hearing Loss among Adults in Albaha Region: A Cross-sectional Study. The Egyptian Journal of Hospital Medicine, 70(5):824-827.

Aslpoor N.D., \& Amirnejad G. (2016). Effect of Employees'welfare On Job Performance of Staff At The Islamic Azad University, Abadan and Khorramshahr Branches. IIOAB Journal, 7(Suppl 4):419-425.

BPS. (2018). Keadaan Ketenagakerjaan Indonesia Februari 2018. Jakarta: Badan Pusat Statistik.

CDC. (2017). Worker Hearing Loss. U.S. Department of Health \& Human Services : Centers for Disease Control and Prevention.

Cancelliere C., Cassidy J.D., Ammendolia C., \& Côté, P. (2011). Are Workplace Health Promotion Programs Effective At Improving Presenteeism In Workers? A Systematic Review And Best Evidence Synthesis Of The Literature. BMC Public Health, 11(1), 395-406.

Eziyi J.A.E., Akinwumi I.O., Olabanji I.O., Ashaolu O.O., \& Amusa Y.B. (2015). Noise Pollution: Knowledge, Attitudes and Practice of Sawmill 
Workers In Osun State, Nigeria. Nigerian Journal of Health Sciences, 15(1):36-39.

Fadli M.A. (2016). Hubungan Intensitas Kebisingan Dengan Gangguan Pendengaran Pada Pengrajin Pandai Besi Di Kelurahan Massepe Kecamatan Tellu Limpoe Kabupaten Sidrap (Skripsi). Makassar: Fakultas Kesehatan Masyarakat-Universitas Hasanuddin.

Feder K., Michaud D., McNamee J., Fitzpatrick E., Davies, H., \& Leroux, T. (2017). Prevalence of Hazardous Occupational Noise Exposure, Hearing Loss, and Hearing Protection Usage Among A Representative Sample of Working Canadians. Journal Of Occupational And Environmental Medicine, 59(1):92.

Heupa A.B., Gonçalves C.G.D.O., \& Coifman H. (2011). Effects Of Impact Noise on The Hearing of Military Personnel. Brazilian Journal of Otorhinolaryngology, 77(6):747753.

Ismail A.F., Daud A., Ismail Z., \& Abdullah B. (2013). Noise-Induced Hearing Loss Among Quarry Workers In A North-Eastern State Of Malaysia: A Study On Knowledge, Attitude and Practice. Oman Medical Journal, 28(5):331.

Keppler H., Ingeborg D., Sofie D., \& Bart V. (2015). The Effects of A Hearing Education Program On Recreational Noise Exposure, Attitudes and Beliefs Toward Noise, Hearing Loss, and Hearing Protector Devices In Young Adults. Noise \& health, 17(78):253-262.

Kirchner D.B., Evenson E., Dobie R.A., Rabinowitz P., Crawford J., Kopke R., \& Hudson, T.W. (2012). Occupational Noise-Induced Hearing Loss: ACOEM Task Force On Occupational Hearing Loss. Journal of Occupational and
Environmental Medicine, 54(1):106108.

Khoshakhlagh A.H., \& Ghasemi M. (2017). Occupational Noise Exposure and Hearing Impairment among Spinning Workers in Iran. Iranian Red Crescent Medical Journal, 19(5):1-7. Lagat A.C., Mutai B.K., Kosgey I.S., \& Nyahururu K. (2014). Importance of Employee Welfare and Performance: The Case of The UASU At Egerton University, Kenya. European Journal of Business and Management, 6(7):205-211.

Leshchinsky A. (2018). The Impact of Annual Audiograms on Employee's Habits and Awareness Regarding Hearing Protection and Noise Induced Hearing Loss, On and Off the Job. Workplace health \& safety, 66(4):201-206.

Lie A., Skogstad M., Johannessen H.A., Tynes T., Mehlum I.S., Nordby K.C., ... \& Tambs K. (2016). Occupational Noise Exposure and Hearing: A Systematic Review. International Archives Of Occupational And Environmental Health, 89(3):351372.

Lobato D.C.B., De Lacerda A.B.M., Gonçalves C.G.D.O., \& Coifman H. (2014). Auditory Effects Of Exposure To Noise And Solvents: A Comparative Study. International Archives Of Otorhinolaryngology, 18(02):136-141.

Moruri L.O., Evans O.O., \& Jennifer. M.K. Influence Of Employee Welfare Facilities On Their Performance At The Kenya Judiciary Systems In North Rift Kenya. Global Journal of Human Resource Management, 6(1): 26-34.

Muflichatun (2006). Hubungan Antara Tekanan Panas Denyut Nadi Dan Produktivitas Kerja Pada Pekerjaan Pandai Besi Paguyuban Wesi Aji Donorejo Batang (Skripsi). Semarang: Universitas Negeri Semarang. 
Nelson D.I., Nelson, R.Y., ConchaBarrientos M., \& Fingerhut M. (2005). The Global Burden of Occupational Noise-Induced Hearing Loss. American Journal of Industrial Medicine, 48(6):446-458.

Oshima K., Suchert S., Blevins N.H., \& Heller S. (2010). Curing Hearing Loss: Patient Expectations, Health Care Practitioners, And Basic Science. Journal of Communication Disorders, 43(4):311-318.

Pelegrin A.C., Canuet L., Rodríguez Á.A., \& Morales M.P.A. (2015). Predictive Factors of Occupational NoiseInduced Hearing Loss In Spanish Workers: A Prospective Study. Noise \& Health, 17(78):343-349.

Pushpakumari M.D. (2008). The Impact Of Job Satisfaction On Job Performance: An Empirical Analysis. In City Forum, 9(1):89105.

Reddy R.K., Welch D., Thorne P., \& Ameratunga S. (2012). Hearing Protection Use In Manufacturing
Workers: A Qualitative Study. Noise and Health, 14(59):202-209.

Rus R.M., Daud A., Musa K.I., \& Naing L. (2008). Knowledge, Attitude and Practice of Sawmill Workers Towards Noise-Induced Hearing Loss In Kota Bharu, Kelantan. The Malaysian Journal of Medical Sciences, 15(4):28-34.

Sayapathi B.S., Su A.T., \& Koh D. (2014). Knowledge, Attitudes and Practice in Relation to Noise-induced Hearing Loss in Two Factories. Research Journal of Biological Sciences, 9(6):197-204.

Waititu F., Kihara P., \& Senaji T. (2017). Effect of Employee Welfare Programmes On Employee Performance: A Case Study of Kenya Railways Corporation. International Academic Journal of Human Resource and Business Administration, 2(3):611-631.

World Health Organization. (2019). Deafness and Hearing Loss. Geneva : World Health Organization 